\title{
Acute fatty liver of pregnancy: a clinical study of 12 episodes in 11 patients
}

Humberto Reyes, Lorena Sandoval, Andres Wainstein, Jose Ribalta, Sergio Donoso, Gladys Smok, Helmar Rosenberg, Manuel Meneses

\begin{abstract}
Twelve episodes of acute fatty liver of pregnancy (AFLP) were diagnosed in 11 patients during the past 18 years in a general hospital in Santiago, Chile, with a prevalence of 1 per 15900 deliveries. Acute fatty liver of pregnency started between the 31st and 38th weeks of pregnancy, with malaise, vomiting, jaundice, and lethargy as the main clinical manifestations. Polydipsia (in nine episodes) and skin pruritus (in seven episodes) were unusual clinical findings. In two patients, pruritus started two and four weeks before AFLP, suggesting that an intrahepatic cholestasis of pregnancy preceded AFLP in those patients. Considering the current prevalence of both diseases in Chile, their association should be considered fortuitous. In another patient, two consecutive pregnancies were affected by AFLP, raising to three the number of reported patients with recurrent AFLP. In 11 episodes, liver biopsies supported the diagnosis of AFLP by showing small and midsized vacuolar cytoplasmic transformation as the most prominent histopathological feature. Positive intracellular fat staining was found in the four samples analysed. Studies by electron microscopy showed megamitochondria with paracrystaline inclusions in four samples. All the mothers survived, but fetal mortality was $58 \cdot 3 \%$. Several extrahepatic complications delayed maternal recovery for up to four weeks after delivery. This study confirms an improvement in maternal prognosis in AFLP, discusses the possibility of an epidemiological association with intrahepatic cholestasis of pregnancy, and increases the number of patients reported with recurrent AFLP. (Gut 1994; 35: 101-106)
\end{abstract}

Acute fatty liver of pregnancy (AFLP) is an uncommon disease with well defined clinical, laboratory, and histopathological features, although none of them are pathognomonic. The first reports mostly described patients with acute or fulminant liver failure during the third trimester of pregnancy that caused high maternal and fetal mortality. ${ }^{1-5}$ Subsequent publications also included patients with a less severe course or those in whom diagnosis was made at an earlier stage of the disease, allowing more opportune and adequate treatment. Concomitantly, prognosis has improved in the mothers and in the babies. ${ }^{6-15}$

The present report describes 12 episodes of AFLP diagnosed in 11 patients taken from an unselected population of pregnant women.
Patients and methods

Between 1975 and 1992, AFLP was diagnosed in 11 white Chilean patients. During the third trimester of a previously normal pregnancy, these patients suddenly developed all or most of the following symptoms, signs, and biochemical abnormalities: malaise, repeated vomiting, encephalopathy, and jaundice with conjugated hyperbilirubinaemia and a mild or moderate hypertransaminasaemia. They had not taken any drugs during pregnancy except low doses of vitamins or iron supplementation. There was no history of alcohol abuse, needle stick injury, blood transfusion, or exposure to patients with hepatitis. Liver function tests (serum total and direct reacting bilirubin, alanine aminotransferase, total alkaline phosphatases, prothrombin time), and other routine laboratory tests (blood glucose, creatinine, urea nitrogen, haemoglobin, white blood cell count and differential analysis, platelet count, and chemical and microscopical analysis of urine) were done serially before and after delivery until all symptoms and signs of liver disease or its complications subsided. Hepatitis B surface antigen was negative in all patients. Hepatitis A IgM antibody (Abbott Laboratories) was available to test the last five patients and was negative during the acute episode. Anti-HCV (Elisa, Abbott Laboratories) was tested once in nine patients, four or more months after the episode of AFLP and was also negative. Ultrasound examination of the biliary tree was normal in all the patients.

Percutaneous liver biopsies were performed in all but one patient who refused this procedure. Paraffin sections were stained by routine methods (haematoxylin and eosin, van Gieson, reticulin). Sudan IV or oil red O staining for fat was also done on frozen sections from four biopsy samples. Four biopsy specimens were studied by electron microscopy, two of them among those that were stained with oil red $O$. The specimens were independently studied by four pathologists previously informed of the clinical and laboratory data.

\section{Results}

EPIDEMIOLOGICAL, CLINICAL, AND LABORATORY FEATURES

These 12 episodes of AFLP were diagnosed during an 18 year period from a total of 190000 deliveries in the department of obstetrics, where the deliveries of about $80 \%$ of the population of women living in the eastern area of Santiago are attended. The estimated mean prevalence of one episode of AFLP for every 15900 deliveries 


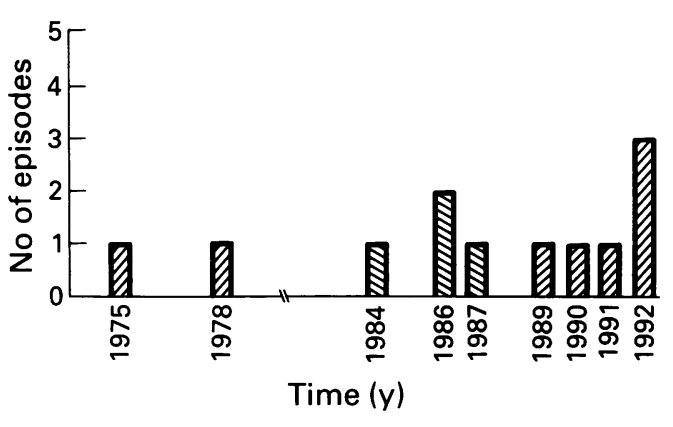

Figure 1: Incidence of acute fatty liver of pregnancy between 1975 and 1992 in a population sample of 190000 deliveries.

is roughly equivalent to 0.7 patients per year but Figure 1 shows that these episodes were unevenly distributed with time and 10 of them $(83 \%)$ were diagnosed during the past seven years.

TABLE I Age, parity, gestational age at onset of the disease, and outcome of pregnancy in 11 patients with 12 episodes of acute fatty liver of pregnancy

\begin{tabular}{|c|c|c|c|c|c|c|c|}
\hline $\begin{array}{l}\text { Patient } \\
\text { No }\end{array}$ & $\begin{array}{l}\text { Age } \\
(y)\end{array}$ & $\begin{array}{l}\text { Parity } \\
(n)\end{array}$ & $\begin{array}{l}\text { Onset of } \\
\text { symptoms } \\
\text { (weeks of } \\
\text { pregnancy) }\end{array}$ & $\begin{array}{l}\text { Interval } \\
\text { between first } \\
\text { symptom and } \\
\text { delivery (days) }\end{array}$ & $\begin{array}{l}\text { Route } \\
\text { of } \\
\text { delivery }\end{array}$ & $\begin{array}{l}\text { Fetal sex } \\
\text { and weight } \\
\text { (g) }\end{array}$ & $\begin{array}{l}\text { Apgar score at one } \\
\text { and five minutes }\end{array}$ \\
\hline $\begin{array}{l}1 \\
2 \\
3 \\
4 \\
5 \\
6 \mathrm{a} \\
6 \mathrm{~b} \\
7 \\
8 \\
9 \\
10 \\
11\end{array}$ & $\begin{array}{l}39 \\
22 \\
16 \\
19 \\
16 \\
28 \\
33 \\
35 \\
30 \\
34 \\
22 \\
27\end{array}$ & $\begin{array}{l}5 \\
1 \\
1 \\
1 \\
1 \\
1 \\
2 \\
1 \\
2 \\
2 \\
1 \\
1\end{array}$ & $\begin{array}{l}32 \\
36 \\
34 \\
36 \\
35 \\
31 \\
36 \\
31 \\
35 \\
38 \\
32 \\
34\end{array}$ & $\begin{array}{r}30 \\
5 \\
5 \\
30 \\
5 \\
4 \\
7 \\
7 \\
7 \\
7 \\
2 \\
14\end{array}$ & $\begin{array}{l}\mathrm{CS} \\
\mathrm{V} \\
\mathrm{V} \\
\mathrm{CS} \\
\mathrm{V} \\
\mathrm{CS} \\
\mathrm{CS} \\
\mathrm{CS} \\
\mathrm{CS} \\
\mathrm{CS} \\
\mathrm{CS} \\
\mathrm{V}\end{array}$ & $\begin{array}{ll}M & 2500 \\
M & 2800 \\
M & 2500 \\
M & 3000 \\
M & 2660 \\
F & 2500 \\
F & 2940 \\
M & 2100 \\
F & 2000 \\
M & 3250 \\
F & 1850 \\
M & 1970\end{array}$ & $\begin{array}{l}\text { (Postnatal death) } \\
\text { (Stillborn) } \\
\text { (Stillborn) } \\
1-3 \\
\text { (Stillborn) } \\
\text { (Stillborn) } \\
9-9 \\
\text { (Stillborn) } \\
8-9 \\
\text { (Stillborn) } \\
4-7 \\
1-6\end{array}$ \\
\hline
\end{tabular}

$\mathrm{V}=$ vaginal delivery; $\mathrm{CS}=$ caesarean section .

TABLE II Clinical manifestations in 12 episodes of acute fatty liver of pregnancy

\begin{tabular}{|c|c|c|c|c|c|c|c|}
\hline $\begin{array}{l}\text { Patient } \\
\text { No }\end{array}$ & Vomiting & $\begin{array}{l}\text { Abdominal } \\
\text { pain }\end{array}$ & Faundice & $\begin{array}{l}\text { Encephalopathy } \\
\text { (stage 0-IV) }\end{array}$ & Polydipsia & Pruritus & Ascitis \\
\hline 1 & + & + & + & II & - & + & - \\
\hline 2 & + & - & + & II & - & + & + \\
\hline 3 & + & - & + & III & + & - & - \\
\hline 4 & + & + & + & II & + & + & + \\
\hline 5 & - & - & + & II & + & - & - \\
\hline $6 a$ & + & - & + & II & + & + & - \\
\hline $6 \mathrm{~b}$ & + & + & + & 0 & + & - & - \\
\hline 7 & + & + & + & III & + & $+^{\star}$ & + \\
\hline 8 & - & + & + & II & - & $+\star \star$ & - \\
\hline 9 & + & - & + & II & + & - & + \\
\hline 10 & + & - & + & I & + & + & - \\
\hline 11 & + & + & + & I & + & - & + \\
\hline
\end{tabular}

^Pruritus and laboratory abnormalities suggesting intrahepatic cholestasis of pregnancy developed several weeks before the onset of symptoms of AFLP.

TABLE III Laboratory findings in 12 episodes of acute fatty liver of pregnancy

\begin{tabular}{|c|c|c|c|c|c|c|}
\hline \multirow[b]{2}{*}{$\begin{array}{l}\text { Patient } \\
\text { No }\end{array}$} & \multicolumn{2}{|l|}{ Bilirubin } & \multirow[b]{2}{*}{$\begin{array}{l}A L T \\
(I U / l)\end{array}$} & \multirow{2}{*}{$\begin{array}{l}\text { Alkaline } \\
\text { phosphatases } \\
\text { (IUIl) }\end{array}$} & \multirow[b]{2}{*}{$\begin{array}{l}\text { Prothrombine } \\
\text { time }(s)\end{array}$} & \multirow{2}{*}{$\begin{array}{l}\text { WBC } \\
\text { count } \\
\left(\times 10^{9} / l\right)\end{array}$} \\
\hline & $\begin{array}{l}\text { Direct } \\
(\mu \mathrm{mol} / \mathrm{l})\end{array}$ & $\begin{array}{l}\text { Total } \\
(\mu \mathrm{mol} / \mathrm{l})\end{array}$ & & & & \\
\hline 1 & 25 & 58 & 65 & 300 & $18 \cdot 8$ & $12 \cdot 0$ \\
\hline 2 & 155 & 225 & 28 & 70 & 19.8 & 24.4 \\
\hline 3 & 160 & 238 & 88 & 175 & $17 \cdot 3$ & $9 \cdot 0$ \\
\hline 4 & 152 & 188 & 149 & 360 & 36.8 & $17 \cdot 6$ \\
\hline 5 & 72 & 85 & 54 & 282 & $17 \cdot 3$ & $19 \cdot 7$ \\
\hline $6 a$ & 171 & 188 & 1200 & 240 & $18 \cdot 8$ & $34 \cdot 2$ \\
\hline $6 b$ & 11 & 31 & 707 & 120 & $11 \cdot 3$ & $9 \cdot 1$ \\
\hline 7 & 88 & 98 & 499 & 300 & $26 \cdot 3$ & $8 \cdot 5$ \\
\hline 8 & 56 & 74 & 38 & 94 & $20 \cdot 3$ & $32 \cdot 0$ \\
\hline 9 & 147 & 297 & 540 & 420 & $19 \cdot 3$ & $18 \cdot 4$ \\
\hline 10 & 65 & 88 & 250 & 120 & $20 \cdot 3$ & $17 \cdot 0$ \\
\hline 11 & 205 & 280 & 169 & 631 & $19 \cdot 3$ & 20.9 \\
\hline
\end{tabular}

Reference values in third trimester of pregnancy: bilirubin direct $<4 \mu \mathrm{mol} / \mathrm{l}$; total $<18 \mu \mathrm{mol} / \mathrm{l}$; alanine aminotransferașe (ALT) $<50$ IU /1; alkaline phosphatases $<400$; prothrombin time $9-12 \mathrm{~s}$; white blood cell (WBC) count 3.2-9.8 $\times 10^{9} / 1$.
Mean age of the patients $(29 \cdot 1$ years) and range (16 to 39 years) were similar to the population of normal pregnant women attending our hospital. Table I shows that most patients (eight) were primigravidas, but one patient had AFLP in her fifth pregnancy. The disease started between the 31 st and 38th gestational weeks and in nine episodes delivery occurred less than one week after the clinical onset of AFLP. Caesarean sections were performed in eight episodes; in five of them because of fetal distress and in the other three because of stillbirth without spontaneous onset of labour. All the mothers survived. Perinatal mortality reached $58 \cdot 3 \%$. Four stillbirths were diagnosed before admission, two during a stay in hospital, and another baby died soon after birth. Their were eight males and four females, with only single pregnancies in this series.

The first symptom was usually malaise. Vomiting soon became prominent in almost every episode. Jaundice and lethargy were the next symptoms, occurring within one to five days (Table II). Encephalopathy was mild or moderate. No mental disturbance was found in patient 6 , episode b. Abdominal pain was infrequent, mild, and unspecific. Polydipsia was relevant in nine episodes, bearing no clear relation to the magnitude of vomiting; patient 5 had polydipsia in the absence of vomiting or other causes of dehydration. Early in the course of the disease ascitis was detected in five patients, clinically or by sonography, and it disappeared spontaneously one or two weeks after delivery. A transient albuminuria $(<3 \mathrm{~g} / \mathrm{l})$ was detected in three episodes. All but one patient remained normotensive during AFLP; patient 11 developed mild pre-eclampsia (hypertension and albuminuria) simultaneously with AFLP.

Table III summarises the main laboratory findings. A direct reacting hyperbilirubinaemia was found in every episode. Alanine aminotransferase activity was mildly or moderately increased, except in patient 6, who had two episodes of AFLP and the highest values of serum aminotransferase activity in the present series. A prothrombin time $>18.8$ seconds coincided in nine episodes with disturbed conciousness, indicating an acute liver failure. Another frequent finding was leucocytosis with neutrophil band forms. Hypoglycaemia was detected in almost all the patients, requiring continuous intravenous infusion of hypertonic glucose for up to one week after delivery.

HISTOPATHOLOGICAL FINDINGS IN LIVER BIOPSIES Small and midsized intracellular vacuoles - without displacement of the nucleus - and ballooning hepatocytes with feather-like cytoplasmic transformation were the most prominent findings under light microscopy and routine staining techniques (Figs 2 and 3). Small foci of inflammatory infiltrates and necrosis were often seen. There were no fibrosis or distortions in the liver plates. Specific staining for fat showed intracellular fat vacuoles in biopsy samples from patients 5, 6 (episode b), 10, and 11. In patient 11 , large fat vacuoles were seen as well as microvesicular fat (Fig 4). Small and midsized intracytoplasmic vacuoles - not membrane 


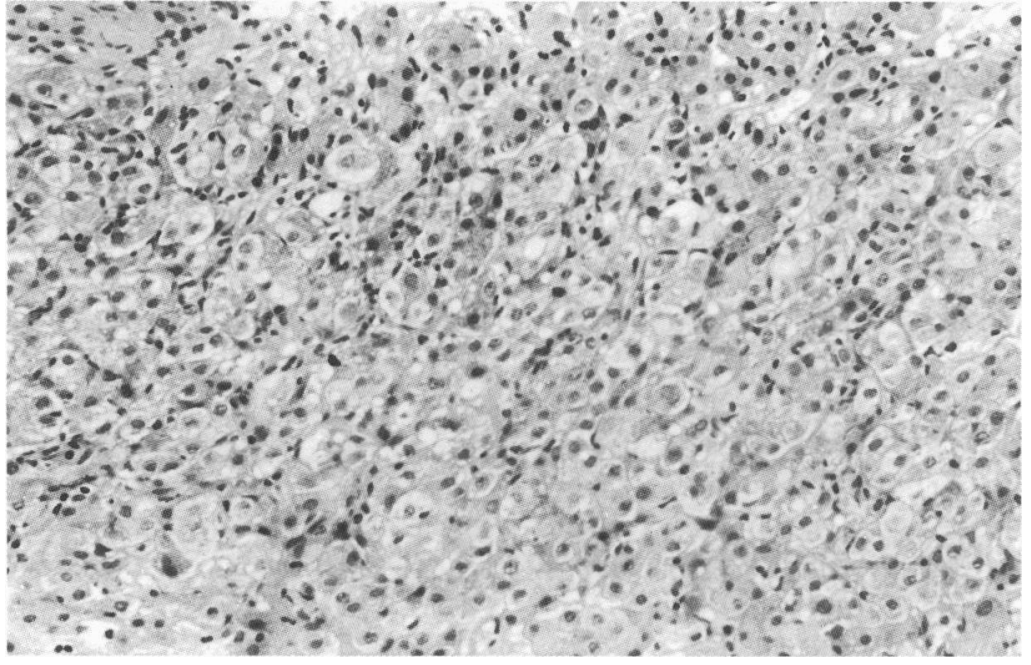

Figure 2: Light microscopy of liver biopsy specimen from patient 6, episode a: hepatocytes are moderately enlarged by small fatty droplets diffusely dispersed throughout the cytoplasm, without displacing the nuclei (haematoxylin and eosin, original magnification $\times 125$ ).

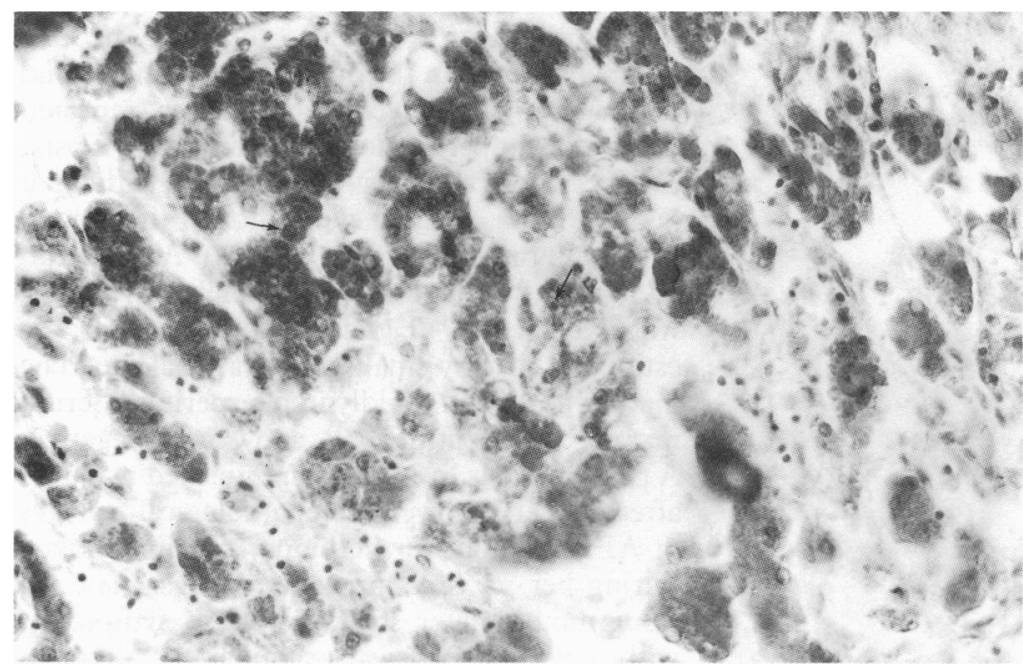

Figure 3: Light microscopy of liver biopsy specimen from patient 6, episode b: small and medium sized fatty droplets (arrows) are diffusely dispersed in the liver (sudan IV, original magnification $\times 200$ ).

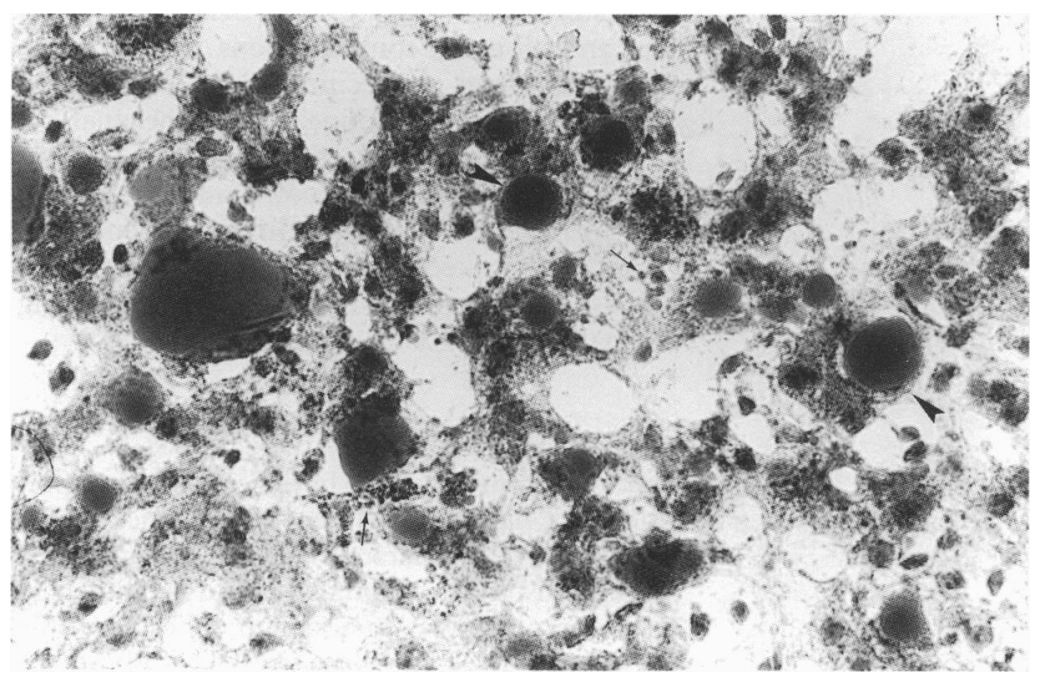

Figure 4: Light microscopy of liver biopsy specimen from patient 11 showing small (arrows) and large (arrow heads) intracellular fat droplets (oil red $O$, original magnification $\times 400$ ). bound - and large, pleomorphic mitochondria with paracrystaline inclusions were evident in the four samples processed for electron microscopy, from patient 6 (episodes $a$ and $b$ ) and from patients 9 and 10 (Figs 5 and 6). In all biopsy samples, the four pathologists who studied them agreed with the diagnosis of AFLP.

\section{COMPLICATIONS}

Extrahepatic events complicated every episode of AFLP, with the exception of episode $b$ in patient 6. Upper gastrointestinal bleeding due to Mallory-Weiss syndrome or a duodenal ulcer, and other haemorrhages attributable to coagulation abnormalities (haemoperitoneum after caesarean section or liver biopsy) occurred in four episodes. Infections (urinary tract infection, endometritis, pneumonia, mastitis) were superimposed in eight episodes. A mild and transient renal failure was detected in five patients. Four episodes had more than one complication. In all patients, these events, and not the initial liver disease, were responsible for the extended duration of postpartum stay in hospital of up to four weeks.

\section{INTRAHEPATIC CHOLESTASIS OF PREGNANCY}

PRECEDING AFLP

Seven patients noticed skin pruritus of mild or moderate severity during the course of AFLP. In two of them, however, the time course of pruritus and other findings led us to postulate that they had first developed intrahepatic cholestasis of pregnancy and that, later on, AFLP was superimposed on it.

Patient 7 had had widespread pruritus of moderate severity since the 29 th week of pregnancy. Two weeks later, she suddenly developed the clinical and laboratory manifestations of an acute liver failure (Tables I-III). A caesarean section was performed after seven days and a stillborn male was delivered. Pruritus faded two days later, while a mild renal failure and ascitis appeared. All the clinical and laboratory alterations subsided after three weeks. A liver biopsy was done 17 days after delivery. It showed extensive microvacuolar cytoplasmic transformation of the hepatocytes, widespread cholestasis, mild pericanalicular inflammatory infiltrates, and isolated foci of cell necrosis.

In patient 8 , the first pregnancy was normal with a spontaneous vaginal delivery at term. During her second pregnancy, pruritus appeared in the 31st week and liver function tests showed a mild increase in serum alanine aminotransferase and in alkaline phosphatases. The diagnosis of cholestasis of pregnancy was made and she was admitted to hospital because of its early onset. Four weeks later, while still in the hospital, she abruptly developed malaise, upper abdominal pain, nausea, and jaundice, with a further increase in serum aminotransferases and alkaline phosphatases. A female baby was delivered by a caesarean section. It weighed $2000 \mathrm{~g}$ with an Apgar score of 8 at one minute. Pruritus faded but her clinical state worsened, with a stage II encephalopathy that lasted two days, a prothrombin time $>20.3$ seconds, and hypo- 


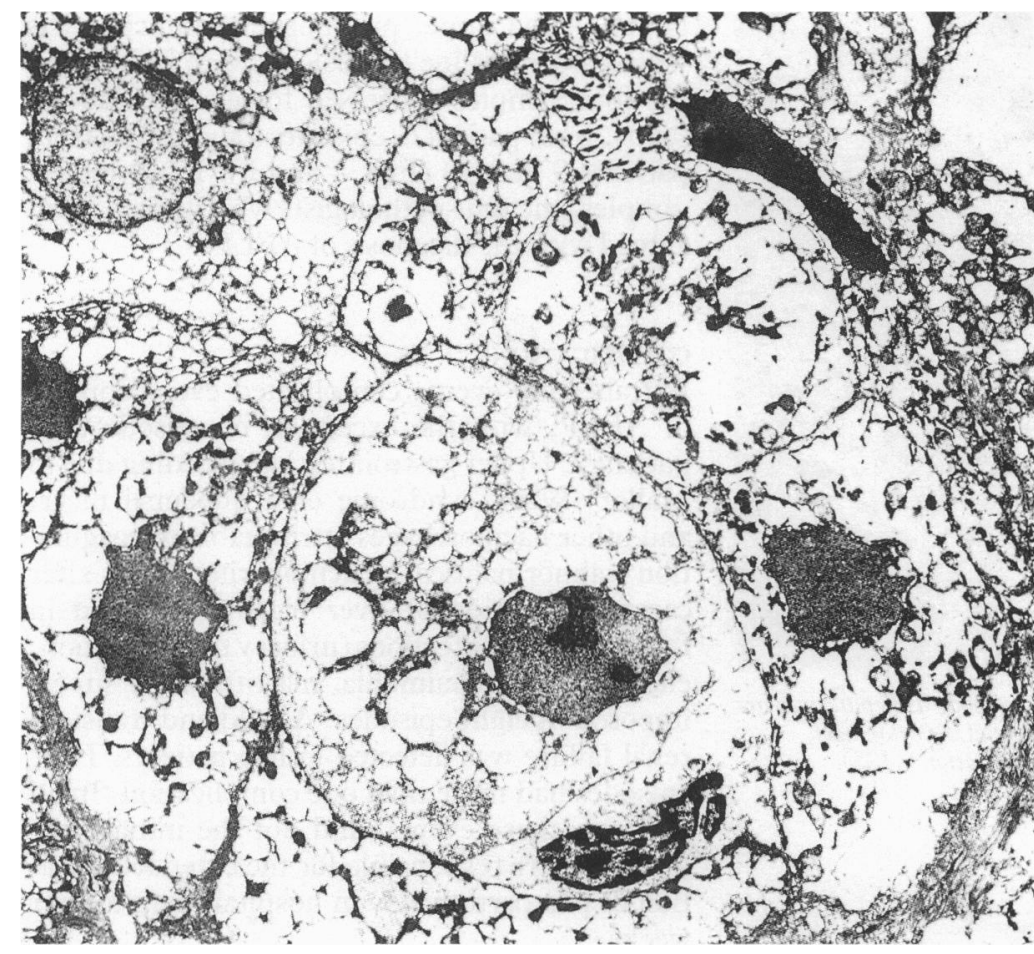

Figure 5: Electron micrograph of liver biopsy specimen from patient 6, episode a: liver cells have many small and medium sized cytoplasmic droplets from $<1 \mu-2 \mu$ in diameter. Specimen obtained from a 1987 paraffin inclusion and reprocessed for transmission electron microscopy (original magnification $\times 3600$ ).

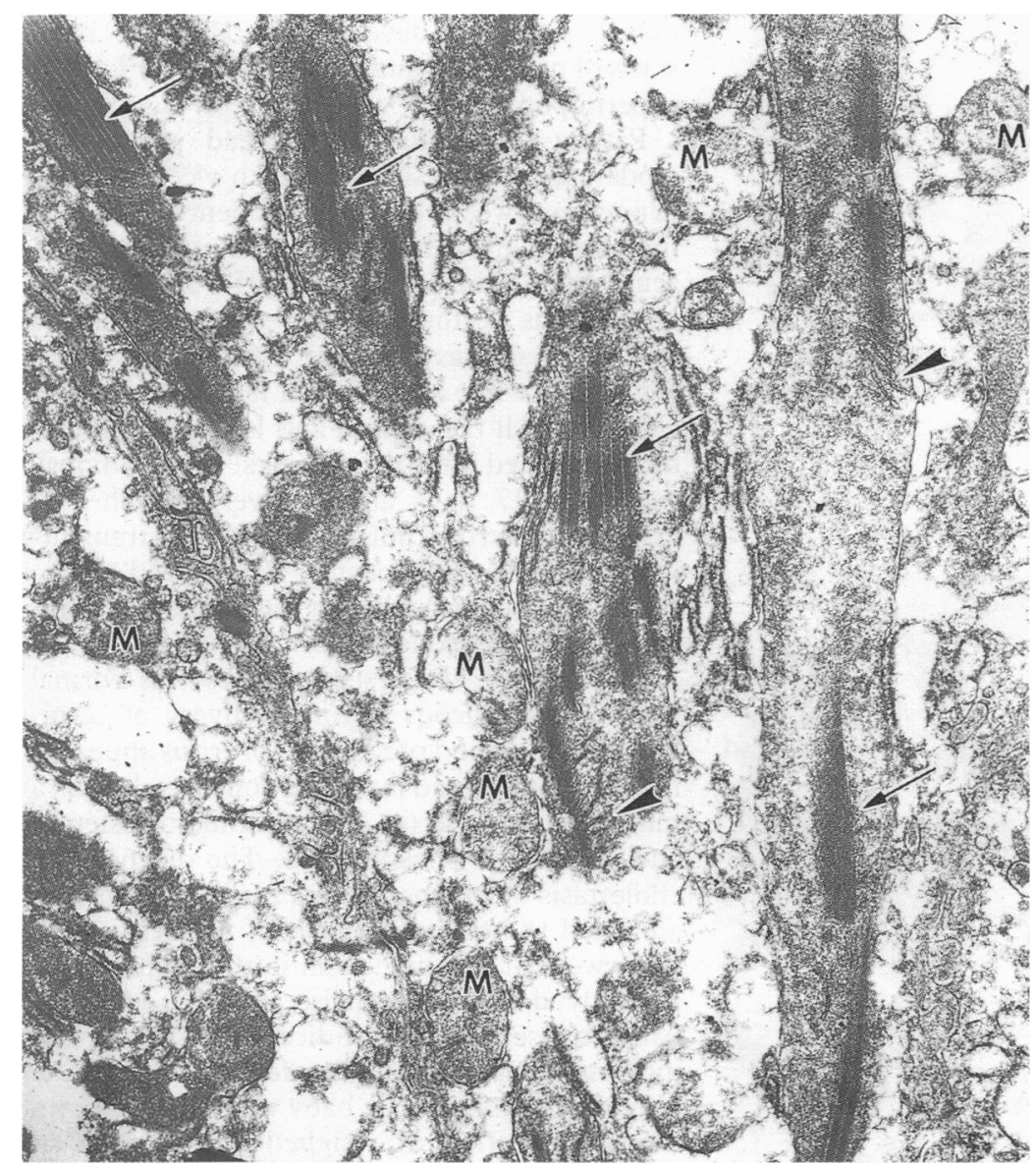

Figure 6: Electron micrograph of liver biopsy specimen from patient 6, episode b: hepatocytes show both normal mitochondria $(M)$ and megamitochondria with several laminar

paracrystaline inclusions (arrows) and some mitochondrial cristae (arrow heads) (fixed in formol, original magnification $\times 18000)$. glycaemia during the first days of puerperium. A liver biopsy was not authorised. She was discharged in good health three weeks after delivery.

Patients 7 and 8 were re-examined three and two years after delivery, respectively. Both appeared healthy. They have not become pregnant again.

OTHER PREGNANCIES IN PATIENTS WITH AFLP

Six gestations that occurred before the pregnancy affected by AFLP (in patients 1,8 , and 9) and one gestation after it (in patient 5) were normal. An unusual clinical event is described in more detail:

\section{A case of recurrent $A F L P$}

Patient 6 was 28 years old when she had a severe AFLP in the 31st week of her first pregnancy (episode 6a in the Tables), with a liver biopsy supporting this diagnosis (Figs 2 and 5). A stillborn female was delivered by caesarean section. The patient remained in good health for the subsequent five years until she became pregnant again. In the 36th week of this second pregnancy, she developed malaise, repeated vomiting, upper abdominal pain, polydipsia, and laboratory abnormalities resembling those of her previous pregnancy, although milder in severity (episode $6 \mathrm{~b}$ in the Tables). A caesarean section was performed immediately, and a girl who weighed $2940 \mathrm{~g}$ was delivered. She was estimated slightly small for gestational age. The mother improved rapidly in puerperium. Serum markers for hepatitis $\mathrm{A}, \mathrm{B}$, and $\mathrm{C}$ were negative. A percutaneous liver biopsy performed two days after delivery showed histopathological features of AFLP similar to the biopsy specimen taken during her previous pregnancy (Figs 3 and 6). Four months later she was free of symptoms, with a normal physical examination, although moderately obese. Liver function tests gave a serum total bilirubin of $20 \mu \mathrm{mol} / \mathrm{l}$, mildly increased alkaline phosphatases, and $\gamma$ glutamyl transpeptidase (1.5 and three times over normal limits, respectively), normal alanine and aspartate aminotransferases, total bile salts, cholesterol, and triglycerides. Serum total protein and albumin concentrations were normal, with a minimal unspecific rise in $\gamma$ globulins. Serum glucose, creatinine, and urine analyses were normal. Determinations of antimitochondrial, antinuclear, antismooth muscle, extractable nuclear, and anticardiolipin (IgG and IgM by enzyme linked immunosorbent assay) antibodies were negative. Her baby was thriving normally with breast feeding.

\section{Discussion}

Previous reports in Chile have detected a low prevalence of AFLP in different geographic areas. ${ }^{+5}$ Ethnic and other characteristics of the population assisted in public hospitals tend to be similar in all geographic areas in Santiago. Therefore, the prevalence detected in the present study in the eastern area of Santiago may be considered as representative of the epidemiological situation of 
the population at large in this city.

The diagnosis of AFLP in our patients was based on the development of an acute liver disease during the final weeks of pregnancy, with the clinical, laboratory, and histopathological features previously reported as characteristic of this disease. ${ }^{3915-19}$ Other causes of acute liver damage that may occur in pregnant women near term cannot be reasonably supported.

The lack of maternal mortality compared with other reports could be due, in part, to less severity of the disease and its complications. None of these patients had hepatic coma. Only two of them reached a stage III encephalopathy. In a previous experience in our hospital, five out of six patients with AFLP were admitted in hepatic coma and they died. ${ }^{20}$ Acute pancreatitis occurred in three of those patients whereas it was not detected in the recent series. Another relevant difference lies in the current availability of intensive care units, providing aggressive supportive care of liver failure and of the severe complications that often endanger maternal survival in AFLP. ${ }^{7-9} 16172122$

Fetal mortality remained high $(58 \cdot 3 \%)$. We endorse the statement that 'good clinical judgement' advises immediate delivery in patients with AFLP although with this policy baby survival has improved less than maternal survival. ${ }^{\text {11-16 23-25 }}$ The rationale of a prompt delivery seems supported by the finding that no patient has yet recovered from AFLP before delivery. " Patients 8 and 11 show (Table I) that AFLP may appear or worsen in puerperium, as previously described. ${ }^{5691625-28}$

In the present series, pre-eclampsia was documented in only one patient (11), despite its frequent association with AFLP..$^{91315}$ Based on epidemiological, clinical, biochemical, and histopathological data, it has been proposed that AFLP and pre-eclampsia may have a close pathogenetic connection - for example, arterial hypertension, renal failure, and kidney lesions with fat accumulation in tubules are often found in patients with AFLP1910 2029-32; hyperuricaemia is a common finding in both diseases and it can be detected several days before their clinical onsets ${ }^{3173-35}$; multiparous patients with AFLP often have a history of pre-eclampsia; AFLP and pre-eclampsia are more frequent in twin pregnancies ${ }^{18}{ }^{19}$; and the microvacuolar fatty transformation of hepatocytes that is considered a hallmark in the histopathological diagnosis of AFLP has also been found in liver biopsies of patients with pre-eclampsia. ${ }^{36}$

By contrast, an association between AFLP and intrahepatic cholestasis of pregnancy, another disease typical of late pregnancy, has not yet been so clearly documented. AFLP and cholestasis of pregnancy have clear cut differences in clinical characteristics, laboratory profile, histopathology, and in maternal prognosis. ${ }^{18} 19$ Cholestasis of pregnancy has a genetic predisposition, but this has not been found for AFLP. Whereas the prevalence of cholestasis of pregnancy in Chile is estimated as $7 \%$ during the past 18 years (a figure considerably higher than in any other country), the prevalence of AFLP in our hospital seems as low as in studies reported from other countries. ${ }^{14} 151819$
Vanjak et al recently reported a patient with pruritus suggestive of cholestasis of pregnancy that started during the 26th week of a first pregnancy. This was followed by the spontaneous delivery of a normal newborn in the 36th week and the development of AFLP immediately postpartum, with complete recovery after one month. ${ }^{37}$ They described this as 'an unusual but favourable association'. Two of our patients ( 7 and 8 in Table 2) also seem to have had both diseases in one pregnancy. Considering their current prevalence in our hospital, however, the relative risk of coexisting both diseases was calculated as 1.43 ; this is slightly above chance (statistical program EPI INFO, version 3.0). The stillbirth that occurred in patient 7 , despite a caesarean section done in the $32 \mathrm{nd}$ week of pregnancy, does not support the postulate of Vanjak et al that an early delivery induced by cholestasis of pregnancy may improve the bad fetal prognosis caused by AFLP.

Polydipsia and polyuria in late pregnancy have been attributed to diabetes insipidus, diabetes mellitus, gestational diabetes, or hypercalcaemia. ${ }^{32} 38$ Only diabetes insipidus has been associated with AFLP. ${ }^{39}$ Polydipsia, with or without polyuria, has also been reported to occur in patients with AFLP. ${ }^{1932}$ Polydipsia was detected in nine episodes in the present series, without polyuria or renal failure and with no relation to the magnitude of vomiting or other causes of dehydration. The symptom had occurred during the days before admission; it was unnoticed by the initial attending obstetricians and therefore no attempts were made before delivery to clarify its pathogenesis. We propose that AFLP should be remembered in the differential diagnosis of causes of polydipsia and malaise of sudden onset in late pregnancy, because these symptoms may precede other more specific manifestations of an acute liver disease..$^{32} 41$

Although the histological picture is a major argument to sustain the diagnosis of AFLP, a careful analysis of clinical, biochemical, and serological data is essential in the differential diagnosis of other causes of microvascuolar fat transformation of liver cells. Liver biopsies often show some degree of cholestasis, inflammation, liver cell necrosis, or large fat vacuoles. ${ }^{915-17}$ The pathologist together with the clinician must consider the patient's clinical background and follow up to compromise with a diagnosis of AFLP. We agree with Riely et $a l^{1317}$ that a liver biopsy is not imperative to guide the obstetrical and medical care of patients with acute liver failure in late pregnancy. The demonstration by electron microscopy of mitochondrial abnormalities in hepatocytes of patients with AFLP has no specific diagnostic value but it should be linked with the recent demonstration of mitochondrial oxidation abnormalities in affected mothers and in their offspring. ${ }^{434}$

The cause of AFLP is unknown. The apparent lack of recurrence in multiparous women has been considered as evidence against a genetic or metabolic 'constitutional' defect. ${ }^{5923}$ Barton et al, however, in Tennessee, reported the case of a black woman who presented with the disease in her fourth and fifth pregnancies, ${ }^{42}$ and in 1991, 
Schoeman et al, in Australia, reported a patient who had AFLP in her first and second pregnancies. $^{43}$ Patient 6 in our series also had two consecutive pregnancies complicated by AFLP and in both episodes the diagnosis was supported by the histopathological findings. These three patients should stimulate the search for pathogenetic factors that could interfere with the normal course of more than one pregnancy in a woman. They now also make the obstetrical counselling of a patient more difficult after recovery from an episode of AFLP.

The low prevalence of AFLP, the fact that it is usually a medical-obstetrical emergency, and the lack of a suitable experimental model, conspire against the possibility of doing prospective studies to identify its cause and to improve its treatment. Therefore, we still have to rely on case reports and retrospective studies to expand our knowledge about this disease.

This study was supported by FONDECYT, Chile (grant 91-1107). We thank Juan Jorge Silva, MD, Unidad de Epidemiología
Clínica, Facultad de Medicina, Universidad de Chile, for statistical assistance.

1 Sheehan HL. The pathology of acute yellow atrophy and delayed chloroforme poisoning. Fournal of Obstetrics and delayed chloroforme poisoning. Fournal of Obste
Gynecology of the British Empire 1940; 47: 49-62.

2 Whiteacre FE, Fang LY. Fatty degeneration of the liver in pregnancy. Report of a case with recovery: chemical and histologic studies. $\mathcal{F A M A}$ 1942; 118: 1358-64

3 Sheehan HL. Jaundice in pregnancy. Am $\mathcal{F}$ Obstet Gynecol $1961 ; 81: 427-40$

4 Zambra G, Cabrera R, Ugarte G, Rubio J, González J. Hígado graso agudo del embarazo. Rev Chil Obstet Ginecol 1968; 33 : 395-402.

5 Armas R, Fajuri A, Chapero L, Gostín L, Reid A, Náquira N. Hígado graso agudo obstétrico. Rev Chil Obstet Ginecol 1973; 38: 214-21.

6 Morrin PAF, Handa SP, Valberg LS, Bencosme SA, Kipkie GF, Willie JC. Acute renal failure in association with fatty liver of pregnancy. Recovery after fourteen days of complete liver of pregnancy. Recovery after fou
anuria. $A m \mathcal{F} M e d ~ 1967 ; 42: 844-51$.

7 Hatfield AK, Stein JH, Greenberger NJ, Abernethy RW, Ferris TF. Idiopathic acute fatty liver of pregnancy: death from extrahepatic manifestations. American fournal of Digestive Diseases 1972; 17: 167-78

8 Cano RI, Delman MR, Pitchumoni CS, Lev R, Rosenthal WS. Acute fatty liver of pregnancy. Complication by disseminated intravascular coagulation. $\mathcal{F A M A} 1975 ; 231$ : 159-61.

9 Burroughs AK, Seong NH, Dojcinov DM, Scheuer PJ, Sherlock SVP. Idiopathic acute fatty liver of pregnancy in twelve patients. QF Med 1982; 204: 481-97.

10 Bernuau J, Degott C, Nouel O, Rueff B, Benhamou JP. Nonfatal acute fatty liver of pregnancy. Gut 1983; 24: 340-4

11 Ebert S, Sun EA, Wright SH, Decker JP, Librizzi RJ Bolognese RJ, Lipschutz WH. Does early diagnosis and Bolognese RJ, Lipschutz WH. Does early diagnosis and
delivery in acute fatty liver of pregnancy lead to improvedelivery in acute fatty liver of pregnancy lead to improve-
ment in maternal and infant survival? Dig Dis Sci 1984; 29: ment in

12 Hou SH, Levin S, Ahola S, Lister J, Omicioli B, Dandrow R, et al. Acute fatty liver of pregnancy. Survival with early cesarean section. Dig Dis Sci 1984; 29: 449-52.

13 Riely CA. Acute fatty liver of pregnancy. Dig Dis Sci 1984; 29: 456-7.

14 Pockros PJ, Reynolds TB. Acute fatty liver of pregnancy [Letter]. Dig Dis Sci 1985; 30: 601-2.

15 Kaplan M. Acute fatty liver of pregnancy. $N$ Engl F Med 1985; 313: $367-70$.

16 Rolfes DB, Ishak KG. Acute fatty liver of pregnancy: a clinicopathologic study of 35 cases. Hepatology 1985; 5: 1149-58.

17 Riely CA, Latham PS, Romero R, Duffy TP. Acute fatty liver of pregnancy: a reassessment based on observation in nine patients. Ann Intern Med 1987; 106: 703-6.
18 Riely CA. Acute fatty liver of pregnancy. Semin Liver Dis 1987; 7:47-54.

19 Van Dyke RW. The liver in pregnancy. In: Zakim D, Boyer TD, eds. Hepatology. A textbook of liver disease. Vol 2. 2nd Ed. Philadelphia: WB Saunders, 1990: 1447-50.

20 Giaconi J, Velasco M, Katz R. Acute fatty metamorphosis of the liver. Acta Gastroenterol Latinoam 1972; 4: 73-8.

21 Holzbach RT. Acute fatty liver of pregnancy with disseminated intravascular coagulation. Obstet Gynecol 1974; 43 : nated

22 Liebman HA, McGehee WG, Patch MJ, Feinstein DI. Severe depression of antithrombin III associated with disseminated intravascular coagulation in women with fatty liver of pregnancy. Ann Intern Med 1983; 98: 330-3.

23 Koff RS. Case records of the Massachusetts General Hospital. Case 4-1981. N Engl F Med 1981; 304: 216-24.

24 Pockros PJ, Peters RL, Reynolds TB. Idiopathic fatty liver of pregnancy: findings in ten patients. Medicine $1984 ; 63: 1-11$.

25 Ockner SA, Brunt EM, Cohn SM, Krul ES, Hanto DW Peters MG. Fulminant hepatic failure caused by acute fatty liver of pregnancy treated by orthotopic liver transplantation. Hepatology 1990; 11: 59-64.

26 Moore HC. Acute fatty liver of pregnancy. Fournal of Obstetrics and Gynecology of the British Empire 1956; 63: 189-98.

27 Douvres PA, Rosenthal WS, Metzer P, Tchertkoff B. Acute fatty liver of pregnancy with hepatic coma and MalloryWeiss syndrome: report of a case. American foumal of Digestive Diseases 1965; 10: 306-13.

28 Bianchi R, Valderrama O, Díaz L, Pisano R. Hígado graso agudo obstétrico. Rev Chil Obstet Ginecol 1983; 48: 108-15.

29 Davies MH, Wilkinson SP, Hanid MA, Portmann B Brudenell JM, Newton JR, Williams R. Acute liver disease with encephalopathy and renal failure in late pregnancy and the early puerperium. A study of fourteen patients. $\mathrm{Br} F$ Obstet Gynecol 1980; 87: 1005-14.

30 Brown MS, Reddy KR, Hensley GT, Jeffers LJ, Schiff ER. The initial presentation of fatty liver of pregnancy mimick-

31 Slater DN, Hague WM. Renal morphological changes in idiopathic acute fatty liver of pregnancy. Histopathology 1984; 8: 567-81.

32 Bourlière $M$, Berman $J$, Ducrotte $S$, Walch $R$, Rueff $B$, Benhamou JP. Polyuro-polydipsie et stéatose hêpatique aiguie gravidique. Discussion à propos d'un cas. $\mathcal{F}$ Gynecol Obstet Biol Reprod 1989; 18: 79-81.

33 Woolf AJ, Johnston AW, Stokes JF, Roberton NRC. Acute liver failure in pregnancy. Case report with survival of mother and child. Fournal of Obstetrics and Gynecology of the British Commonwealth 1964; 71: 914-8.

34 Quigley MM. Acute obstetric yellow atrophy presenting as idiopathic hyperuricemia. South $M e d \mathcal{f} 1974 ; 67$ : 142-4.

35 Hsiung R, Hasselmann M, Lutun T, Gordji M. Un cas de stéatose hépatique aigüe gravidique. Intérêt diagnostique de l'hyperuricémie au stade pré-ictérique. $\mathcal{F}$ Gynecol Obstet Biol Reprod 1988; 17: $901-5$.

36 Minakami H, Oka M, Tadashi S, Sato T, Tamada T, Yasuda Y, Hirota N. Preeclampsia: a microvesicular fat disease of the liver? American foumal of Obstetrics and Gynecology 1988; 159: 1043-7.

37 Vanjak D, Moreau R, Roche-Sicot J, Soulier A, Sicot C Intrahepatic cholestasis of pregnancy and acute fatty liver of pregnancy. An unusual but favourable association? Gastroenterology 1991; 100: 1123-5.

38 Durr JA, Hoggard JG, Hunt JM, Schrier RW. Diabetes insipidus in pregnancy associated with abnormally high circulating vasopressinase activity. $N$ Englf $M e d$ 1987; 314: $1070-4$.

39 Cammu H, Velkeniers B, Charels K, Vincken W, Amy JJ. Idiopathic acute fatty liver of pregnancy associated with transient diabetes insipidus. Case report. Br $\mathcal{F}$ Obstet Gynecol 1987; 94: 173-8.

40 Bacq Y, Constans T, Body G, Choutet P, Lamisse F. La stéatose hépatique aigüe gravidique. $\mathcal{F}$ Gynecol Obstet Biol Reprod 1986; 15: 851-61.

41 Berardi JC, Fraysse B, Bernuau J, Descout F, Akli J, BerardiGrassias L. La stéatose hépatique aigüe gravidique. f Gynecol Obstet Biol Reprod 1983; 12: 263-8.

42 Barton JR, Sibai BM, Mabie WC, Shanklin DR. Recurrent acute fatty liver of pregnancy. American fournal of Obstetrics and Gynecology 1990; 163: 534-8.

43 Schoeman MN, Batey RG, Wilcken B. Recurrent acute fatty liver of pregnancy associated with a fatty-acid oxidation defect in the offspring. Gastroenterology 1991; 100: 544-8.

44 Treem WR, Rinaldo P, Hale D, Stanley C, Turnbull D, Millington D, Hyams J. Acute fatty liver of pregnancy and long-chain 3-hydroxyacyl CoA dehydrogenase (LCHAD) long-chain 3-hydroxyacyl CoA dehydrogenase (LCHAD)
deficiency: a possible link [abstract]. Hepatology 1992; 16: d9A. 